\title{
Dapsone treatment is efficient against persistent cutaneous and gastrointestinal symptoms in children with Henoch-Schönlein purpura
}

\author{
Jana Volejnikovaa, Jaroslav Horacek ${ }^{\mathrm{b}}$, Frantisek Kopriva ${ }^{\mathrm{a}}$
}

\begin{abstract}
Background. Henoch-Schönlein purpura (HSP) is a systemic disorder characterized by leukocytoclastic vasculitis involving the capillaries and by the deposition of IgA immune complexes. An association between HSP and atypical bacteria is uncommon in children.

Methods and Results. Here we report three cases of children, aged 5, 4 and 16 years, who were diagnosed with HSP associated with Mycoplasma pneumoniae or Chlamydia pneumoniae infection. In all presented cases, persistent cutaneous manifestations and abdominal pain were resistant to antibiotics and corticosteroids, but resolved during $48 \mathrm{~h}$ after the introduction of dapsone. No adverse effects of treatment were observed.

Conclusion. Dapsone, a sulphone with an anti-inflammatory activity, showed remarkable therapeutic efficacy against rash and gastrointestinal symptoms in children with HSP. Its administration should be considered particularly in persistent cutaneous form of HSP.
\end{abstract}

Key words: atypical bacteria, children, Henoch-Schönlein purpura, dapsone

Received: May 29, 2017; Accepted: October 6, 2017; Available online: November 2, 2017 https://doi.org/10.5507/bp.2017.044

${ }^{a}$ Department of Pediatrics, Faculty of Medicine and Dentistry, Palacky University Olomouc and University Hospital Olomouc, Czech Republic ${ }^{b}$ Department of Clinical and Molecular Pathology, Faculty of Medicine and Dentistry, Palacky University Olomouc and University Hospital Olomouc, Czech Republic

Corresponding author: Frantisek Kopriva, e-mail: frantisek.kopriva@fnol.cz

\section{INTRODUCTION}

Henoch-Schönlein purpura (HSP) is a small vessel vasculitis resulting from immunoglobulin A (IgA)-mediated inflammation. It is the most common acute systemic vasculitis of childhood mainly affecting skin, gastrointestinal tract, joints and kidneys. Increased polymeric IgA production by mucosal immune system in response to a mucosally presented antigen, such as bacteria, viruses, or fungi, has been considered an underlying mechanism for HSP. In an acute phase of HSP, increased concentrations of pro-inflammatory cytokines which can cause damage to the endothelium such as TNF- $\alpha$, can be detected ${ }^{1}$. HSP is usually self-limiting with spontaneous resolution of symptoms within 2 months, however, recurrence occurs in approximately one third of cases ${ }^{2}$. Relapses mostly manifest as a new episode of rash that is often associated with gastrointestinal and renal symptoms. Articular and gastrointestinal involvement at the time of diagnosis is predictive of relapse ${ }^{2}$. Some patients suffer from chronic cutaneous form of HSP and recurrent abdominal pain.

Arthralgia and painful soft tissue edema usually respond to acetaminophen or nonsteroidal anti-inflammatory drugs. Oral prednisone $(1-2 \mathrm{mg} / \mathrm{kg}$ day) may be necessary to accelerate their effect, however, corticosteroid therapy does not prevent the development of progressive renal disease. Immunosuppressants (azathioprine, oral cyclophosphamide and mycophenolate) are used as corticosteroid-sparing agents or as an add-on therapy in patients with severe renal involvement ${ }^{3}$. Sporadic reports suggest that dapsone may accelerate resolution of the palpable rash (Table 1) $\left(\right.$ ref. $^{4-12}$ ).

Here we report three cases of HSP associated with atypical bacterial infections - Mycoplasma pneumoniae and Chlamydia pneumoniae - with relapsing cutaneous manifestations and abdominal pain, which were alleviated by dapsone treatment. Diagnosis of HSP was based on the criteria of the Paediatric Rheumatology European Society (PRES), European League Against Rheumatism (EULAR) and Pediatric Rheumatology International Trials Organisation (PRINTO) (ref. ${ }^{13-16}$ ).

\section{CASE REPORT 1}

A previously healthy 5-year-old girl was admitted to a regional hospital due to periumblical pain and severe palpable purpuric rash involving buttocks and legs. Oral penicillin was given for 10 days due to positivity of the pharyngeal swab for Streptococcus pyogenes, however, her general condition worsened and purpuric lesions extended to the arms, abdomen and face. Oral prednisone $(2 \mathrm{mg} / \mathrm{kg} /$ day) was ineffective in controlling skin lesions and abdominal pain. After transferring to our department, she had leukocytosis (WBC; $21,900 / \mu \mathrm{L}$ ), elevated C-reactive protein (CRP; $37 \mathrm{mg} / \mathrm{dL}$ ) and D-dimers ( 865 $\mathrm{ng} / \mathrm{mL}$ ). Stool analysis revealed occult blood while urinalysis was negative. Chlamydia-specific IgM antibodies were positive (Chlamydia IgG, IgM, IgA r-ELISA, EIA, MEDAC Germany). Other possible autoimmune condi- 
tions and infections (such as EBV, CMV, hepatitis A, B, C, Yersinia and Mycoplasma) were excluded. Skin biopsy from the lesion showed infiltration of small vessels in the dermis by leukocytes with nuclear dust and extravasation of erythrocytes confirming leukocytoclastic vasculitis. Clarithromycin at a dose of $15 \mathrm{mg} / \mathrm{kg} /$ day was given for 14 days, however, abdominal pain and purpura on the legs reappeared 1 week after its cessation. Dapsone $(0.5$ $\mathrm{mg} / \mathrm{kg} /$ day) was introduced 2 months after HSP onset. Due to persisting purpura and abdominal pain after 2 weeks, the dose was increased to $1 \mathrm{mg} / \mathrm{kg} /$ day followed by regression of rash and relief from abdominal pain within $48 \mathrm{~h}$. The treatment was finished after 6 weeks without any adverse effect (methemoglobin level was 1.6\%). Less intense palpable purpura occurred four times during the next 12 months.

\section{CASE REPORT 2}

A 4-year-old boy was admitted to a regional hospital with two-week history of rhinitis, nausea, vomiting and abdominal pain. One day later, he developed palpable purpuric rash involving buttocks and legs and angioedema (non-pitting edema) of eyelids and face. Laboratory tests showed leukocytosis (WBC 34,000/ $\mu \mathrm{L}$ ) and elevated CRP (31.4 mg/dL). Fecal occult blood test was positive. Amoksiklav was given for 10 days due to incidental tonsilitis and prednisone $(2 \mathrm{mg} / \mathrm{kg} /$ day $)$ was added due to recurrent abdominal pain for two weeks. The boy was transferred to our department, where we excluded infections with Streptococcus, Helicobacter, Yersinia, Chlamydia, Coxsackie, hepatitis, CMV, EBV, parvovirus and Toxocara, but confirmed positivity of Mycoplasma pneumoniae antibodies (LIAISON Mycoplasma pneumoniae IgM, IgG, DIASORIN Ireland, CLIA). Clarithromycin (15 mg/ $\mathrm{kg}$ /day) was continued for 14 days. Subsequently, due to recurrent abdominal pain and purpura, dapsone $(1 \mathrm{mg} /$ $\mathrm{kg}$ /day) was given for 4 weeks and symptoms completely resolved within $48 \mathrm{~h}$.

\section{CASE REPORT 3}

A 16-year-old boy was treated by dermatologist for a non-pruritic maculopapular rash of legs with topical beclomethasone dipropionate. Within two months, ecchymoses and petechiae appeared on his legs, arms and trunk despite treatment. Clarithromycin was given for 21 days due to elevated titer of Mycoplasma pneumoniae antibodies without improvement of the skin lesions. At our clinic, other causative agents and autoimmune disorders were excluded. Dapsone $(1 \mathrm{mg} / \mathrm{kg} /$ day $)$ was introduced after 6 months from disease onset followed by marked improvement within a few days (Fig. 1).

The patients' parents provided informed consent for publication.
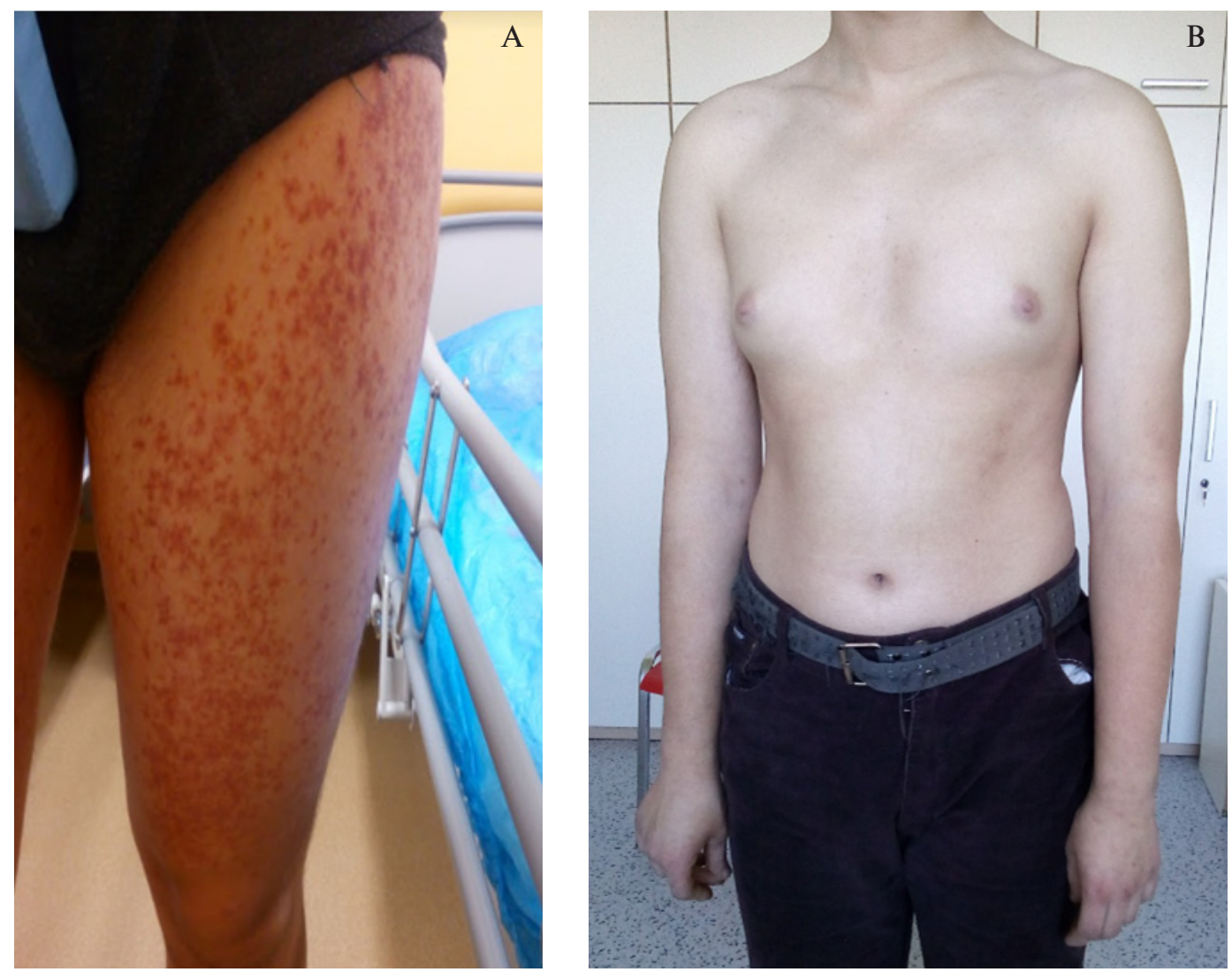

Fig. 1. Ecchymoses and petechiae in a 16-year-old boy with Henoch-Schönlein purpura associated with Mycoplasma pneumoniae (A) before introduction of dapsone, (B) several days after administration of dapsone. 


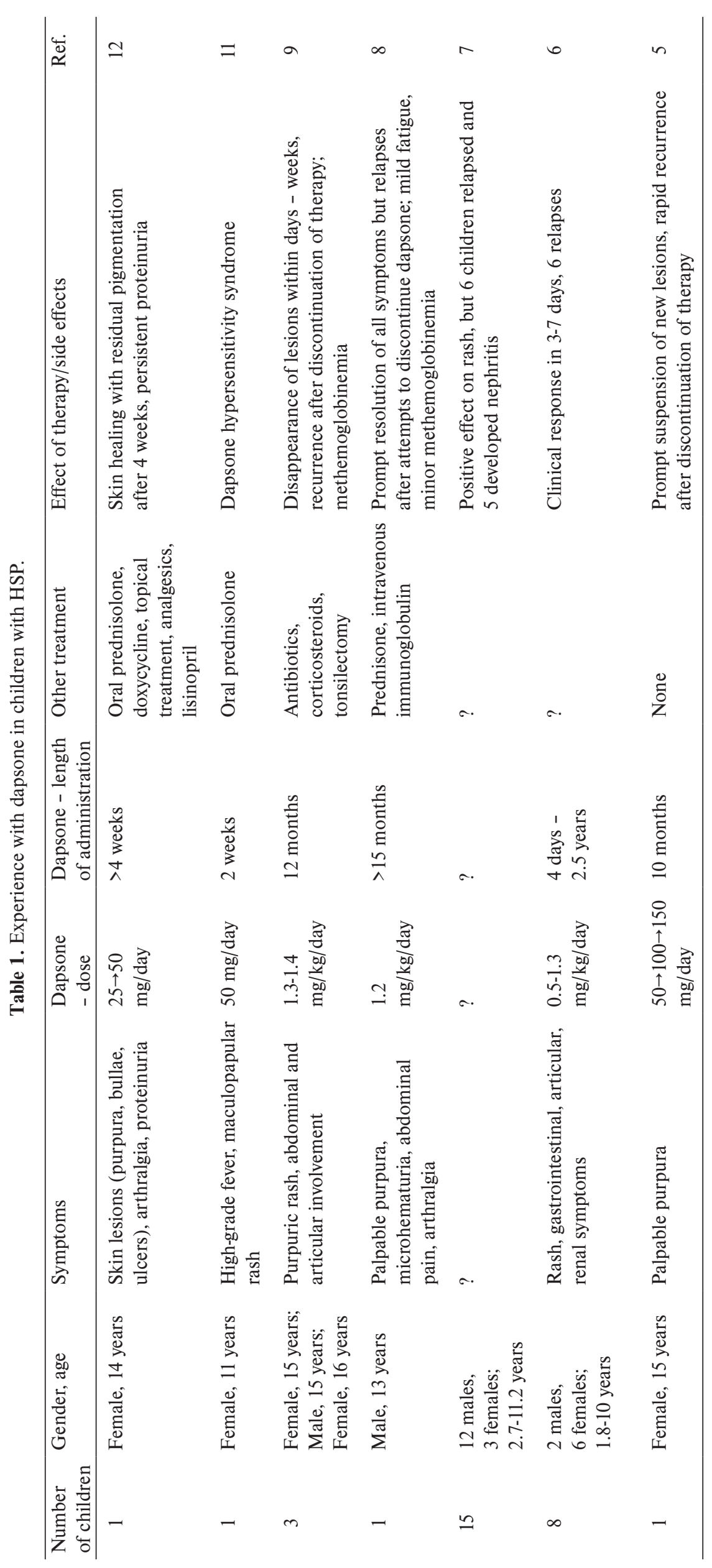




\section{DISCUSSION}

Association of HSP with atypical bacterial infections may occur but is infrequent in children ${ }^{17-19}$. Interestingly, patients who suffered relapse of HSP had less frequent history of upper respiratory tract infections ( $31 \%$ vs. $42 \%$ ) $\left(\right.$ ref. $\left.^{2}\right)$.

Dapsone (diaminodiphenylsulfone) was first synthesized in 1908 by Fromm and Whittmann. During the 1950s, sulfones were shown to possess an anti-inflammatory activity in dermatitis herpetiformis and subcorneal pustular dermatosis (Sneddon-Wilkinson syndrome) and their anti-inflammatory properties have increasingly been used in the treatment of dermatologic disorders ${ }^{20}$. In vitro studies demonstrated that dapsone inhibits neutrophil myeloperoxidase-mediated iodination and cytotoxicity at concentrations comparable to therapeutic serum levels. Therefore, dapsone appears to protect cells from neutrophil- and eosinophil-mediated injury by directly inhibiting the generation of oxygen-derived radicals. Systemic dapsone reduces leukotriene B4 (LTB4)-stimulated inflammation in mice by inhibiting the binding of LTB4 to specific receptors on neutrophils and by inhibiting neutrophil chemotactic response to LTB4. Dapsone inhibits the generation of 5-lipooxygenase products in human polymorphonuclear leukocytes and rat mast cells in vitro and also inhibits lysosomal enzymes. Therefore, by multiple mechanisms, dapsone reduces the release of prostaglandins and leukotrienes and blocks their inflammatory effects ${ }^{20,21}$.

First reports on dapsone treatment in HSP were published as soon as in the $1980 \mathrm{~s}^{4,5}$. However, the number of reported cases is still low probably due to a small proportion of severe persistent cases and availability of other immunosupressive agents (such as azathioprine, cyclophosphamide, methotrexate and mycophenolate). Published reports on the use of dapsone in children with HSP are summarized in Table 1.

Prognosis of HSP clearly depends on the presence of renal involvement and dapsone was shown to be ineffective in the control of HSP nephritis ${ }^{6,7}$. Nevertheless, its rapid effectivity against persistent, predominantly cutaneous, manifestations of HSP was confirmed both in previous studies and by our data. The onset of effect is rapid, taking from few days to several weeks, however, recurrence of symptoms after cessation of treatment is common.

The dosage of dapsone in the presented studies ranged between $0.5 \mathrm{mg} / \mathrm{kg} /$ day and $150 \mathrm{mg} /$ day with the most frequently used dose of $1 \mathrm{mg} / \mathrm{kg} /$ day (Table 1 ). As we aimed to prevent possible side effects, our first patient started with a lower dose of dapsone $(0.5 \mathrm{mg} / \mathrm{kg} /$ day $)$ with insufficient effect, whereas a dose of $1 \mathrm{mg} / \mathrm{kg} /$ day was proved to be safe and effective.

Dapsone demonstrated a favorable safety profile with rare and easily manageable adverse effects such as hypersensitivity syndrome or methemoglobinemia ${ }^{9,11}$. This gives dapsone a significant advantage over corticosteroids and other immunosupressive agents. Therefore, dapsone should be considered for treatment of persistent purpura and abdominal pain in HSP especially in patients without renal involvement, such as in our three cases.

\section{CONCLUSION}

This is a report of three children with HenochSchönlein purpura (HSP) underlined by infection with Mycoplasma pneumoniae or Chlamydia pneumoniae, who presented with persistent rash and gastrointestinal symptoms resistant to standard treatment. In all cases, introduction of dapsone led to fast regression of symtoms without any reported adverse effects. We provide a comprehensive review of published pediatric cases with conclusion that dapsone treatment is beneficial especially in cases of persistent skin lesions in HSP.

Acknowledgement: Supported by grant from the Czech Ministry of Education, Youth and Sports (NPU LO 1304).

Author contributions: FK: study design and supervision; JV and FK: clinical management, data collection, literature search and manuscript writing; JH: histopathological examinations. All co-authors have read the final manuscript within their respective areas of expertise and participated sufficiently in the study to take responsibility for it and accept its conclusions.

Conflicts of interest statement: The authors state that there are no conflicts of interest regarding the publication of this article.

\section{REFERENCES}

1. Roberts PF, Waller TA, Brinker TM, Riffe IZ, Sayre JW, Bratton RL. Henoch-Schönlein purpura: a review article. South Med J 2007;100(8):821-4.

2. Calvo-Rio V, Hernandes JL, Ortiz-Sanjuan F, Loricera J, PalmouFontana N, González-Vela MC, González-Lamuño D, González-López MA, Armesto S, Blanco R, González-Gay MA. Relapses in patients with Henoch-Schönlein purpura: Analysis of 417 patients from a single center. Medicine (Baltimore) 2016;95(28):e4217.

3. Saulsbury FT. Henoch-Schönlein purpura in children. Report of 100 patients and review of the literature. Medicine (Baltimore) 1999;78(6):395-409.

4. Ledermann JA, Hoffbrand BI. Dapsone in allergic vasculitis: its use in Henoch-Schönlein disease following vaccination. J R Soc Med 1983;76(7):613-4

5. Fredenberg MF, Malkinson FD. Sulfone therapy in the treatment of leukocytoclastic vasculitis. Report of three cases. J Am Acad Dermatol 1987;16(4):772-8.

6. Iqbal H, Evans A. Dapsone therapy for Henoch-Schonlein purpura: a case series. Arch Dis Child 2005;90(9):985-6.

7. Shin JI, Lee JS, Chung KS. Dapsone therapy for Henoch-Schonlein purpura. Arch Dis Child 2006;91(8):714.

8. Papandreou T, Dürken M, Goebeler M, Hoeger PH, Goerdt S, Peitsch WK. Chronic recalcitrant Henoch-Schönlein purpura: successful treatment with dapsone. Eur J Dermatol 2010;20(5):639-40.

9. Mazille N, Lipsker D, Fischbach M. Dapsone for chronic skin lesions in 3 children suffering from Henoch-Schönlein vasculitis. Arch Pediatr 2011;18(11):1201-4.

10. Bech AP, Reichert LJ, Cohen Tervaert JW. Dapsone for the treatment of chronic IgA vasculitis (Henoch-Schonlein). Neth J Med 2013;71(4):220-1. 
11. Jayavardhana A, Vijayalakshmi AM. Dapsone hypersensitivity syndrome during Henoch-Schonlein purpura treatment. Indian Dermatol Online J 2014;5:93-4.

12. Chen CB, Garlapati S, Lancaster JD, Zinn Z, Bacaj P, Patra KP. Bullous Henoch-Schönlein purpura in children. Cutis 2015;96(4):248-52.

13. Mills JA, Michel BA, Bloch DA, Calabrese LH, Hunder GG, Arend WP Edworthy SM, Fauci AS, Leavitt RY, Lie JT. The American College of Rheumatology 1990 criteria for the classification of HenochSchönlein purpura. Arthritis Rheum 1990;33(8):1114-21.

14. Ozen S, Ruperto N, Dillon MJ, Bagga A, Barron K, Davin JC, Kawasaki T, Lindsley C, Petty RE, Prieur AM, Ravelli A, Woo P. EULAR/PreS endorsed consensus criteria for the classification of childhood vasculitides. Ann Rheum Dis 2006;65(7):936-41.

15. Ozen S, Pistorio A, Iusan SM, Bakkaloglu A, Herlin T, Brik R Buoncompagni A, Lazar C, Bilge I, Uziel Y, Rigante D, Cantarini L, Hilario MO, Silva CA, Alegria M, Norambuena X, Belot A, Berkun Y, Estrella Al, Olivieri AN, Alpigiani MG, Rumba I, Sztajnbok F, TambicBukovac L, Breda L, Al-Mayouf S, Mihaylova D, Chasnyk V, Sengler C, Klein-Gitelman M, Djeddi D, Nuno L, Pruunsild C, Brunner J, Kondi A Pagava K, Pederzoli S, Martini A, Ruperto N; Paediatric Rheumatology International Trials Organisation (PRINTO). EULAR/PRINTO/PRES criteria for Henoch-Schönlein purpura, childhood polyarteritis nodosa, childhood Wegener granulomatosis and childhood Takayasu arteri- tis: Ankara 2008. Part II: Final classification criteria. Ann Rheum Dis 2010;69(5):798-806

16. Ortiz-Sanjuan F, Blanco R, Hernandez JL, González-López MA, Loricera J, Lacalle-Calderón M, Pina T, Calvo-Río V, Álvarez L, González-Vela MC, Rueda-Gotor J, González-Gay MA. Applicability of the 2006 European League Against Rheumatism (EULAR) criteria for the classification of Henoch-Schönlein purpura. An analysis based on 766 patients with cutaneous vasculitis. Clin Exp Rheumatol 2015;33(2 Suppl 89):S44-7.

17. Beltran Garcia S, Dominiquez Cajal M, Lafuente Hidalgo M García Sánchez N, Benito Ruesca R. Henoch-Schönlein purpura and Chlamydophila pneumoniae. An Pediatr 2008;68(2):196-7.

18. Kuźma-Mroczkowska E, Pańczyk-Tomaszewska M, Szmigielska A, Szymanik-Grzelak H, Roszkowska-Blaim M. Mycoplasma pneumoniae as a trigger for Henoch-Schönlein purpura in children. Cent Eur J Immunol 2015;40(4):489-92.

19. Terraneo L, Lava SA, Camozzi P, Zgraggen L, Simonetti GD, Bianchetti MG, Milani GP. Unusual Eruptions Associated with Mycoplasma pneumoniae Respiratory Infections: Review of the Literature. Dermatology 2015;231(2):152-7.

20. Ford PG. Dapsone. Curr Probl Dermatol 2000;12(5):242-5.

21. Zhu YI, Stiller MJ. Dapsone and sulfones in dermatology: overview and update. J Am Acad Dermatol 2001;45(3):420-34. 